\title{
Plasma Levels of Arginine Vasopressin Elevated in Patients with Major Depression
}

Liesbeth van Londen, M.D., Jaap G. Goekoop, M.D., Ph.D., Godfried M. J. van Kempen, Ph.D., Ank C. Frankhuijzen-Sierevogel, Victor M. Wiegant, Ph.D., Edo A. van der Velde, David De Wied, M.D., Ph.D.

Mentally healthy subjects show increased plasma concentrations of the neuropeptides, arginine vasopressin (AVP) and oxytocin (OT), under conditions of stress, but data are lacking about plasma concentrations of $A V P$ and OT in patients with major depression. We thus assessed plasma concentrations of AVP and OT in patients with major depression $(n=52)$ and healthy controls $(n=37)$. Mean plasma AVP concentrations were higher in the group of depressed patients than in controls. A subgroup of 16 patients showed very high levels of plasma AVP, but no other feature differentiating this subgroup from the other patients was found. In-patients showed higher plasma AVP levels than out-patients, and melancholic patients had higher plasma $A V P$ levels than did nonmelancholic patients. Plasma AVP levels were slightly related to psychomotor retardation and significantly inversely to neuroticism. Patients' plasma OT concentrations had a wider range than in controls. AVP and AVP-mediated functions may be a factor in the clinical picture of depression, possibly by influencing the activity of the hypothalamic-pituitary-adrenal axis.

[Neuropsychopharmacology 17:284-292, 1997]

(C) 1997 American College of Neuropsychopharmacology. Published by Elsevier Science Inc.
KEY WORDS: Arginine vasopressin; Oxytocin; Cortisol; Major depressive episode; Neuroticism; Psychomotor retardation

Three lines of evidence suggest that the hypothalamohypophyseal neuropeptides, arginine vasopressin (AVP) and oxytocin (OT), are involved in mood disorders. First, animal studies have demonstrated that vasopressin and OT function as neuromodulators of the stress response (Gibbs 1986; Ivanyi et al. 1991; Bartanuzs et al. 1993). Human studies have shown that plasma concentrations of AVP increase or decrease depending on dif-

From the Department of Psychiatry (LvL, JCG, GMJvK) and the Department of Medical Statistics (EAvdV), Leiden University; and the Rudolf Magnus Institute for Neurosciences, Department of Medical Pharmacology (ACFS, VMW, DDW), Utrecht University, The Netherlands.

Address correspondence to: Dr. L. van Londen, Department of Psychiatry, Leiden University, PO Box 1251, 2340 BG Oegstgeest, The Netherlands.

Received December 14, 1996; accepted February 13, 1997. ferent conditions of stress, whereas normal release is predominantly controlled by osmo- and volume receptors (Edelson and Robertson 1986). As examples, AVP levels increase when healthy subjects are exposed to a severe psychological stressor (Meyerhoff et al. 1990), to social isolation and confinement (Maillet et al. 1993), and pain (Kendler et al. 1978). However, AVP levels decrease during anticipation of pain (Edelson and Robertson 1986). Healthy human subjects exposed to uncontrollable noise have increased plasma OT levels (Sanders et al. 1990, Fruhstorfer et al. 1986).

Second, an increased hypothalamic-pituitary-adrenocortical (HPA) activity is found in $40-90 \%$ of patients with major depression (Holsboer 1996). Holsboer (1995) postulated the hypothesis that the mechanisms underlying these findings comprise weakened corticosteroid receptor function in hippocampus and hypothalamus, leading to enhanced synthesis and release of corticotropin-releasing hormone (CRH) and AVP. CRH neurons in the paraventricular nucleus (PVN) of the hypothala- 
mus coexpress AVP, and AVP synergizes with CRH to produce an overdrive of the pituitary adrenocortical system. Purba et al. (1996) found evidence of an increased vasopressinergic drive in depression when they showed an increased number of AVP- and OT-expressing neurons in the PVN of depressed patients.

Third, central AVP-mediated functions, such as attention, memory, nociception, and circadian rhythms are frequently disturbed in affective disorders (Gold et al. 1978). The suprachiasmatic nuclei (SCN) are thought to be involved in the regulation of circadian rhythms and contain AVP-synthesizing neurons (Stopa et al. 1984). These neurons project exclusively inside the central nervous system (CNS) and do not contribute directly to changes in plasma concentrations of AVP. However, AVP-containing neurons of the SCN do project to the paraventricular region of the hypothalamus (Watts and Swanson 1987) and can therefore indirectly influence the resulting plasma levels of AVP.

Based on these three lines of evidence, changes in plasma and cerebrospinal fluid (CSF) levels of AVP and OT could be expected in patients with major depression, but such a change has never been shown convincingly. We aimed to study plasma concentrations of AVP and OT in a large sample of drug-free patients with a major depressive episode and in healthy controls. AVP and OT were measured at three time points in the day, and their concentrations in plasma were evaluated in relation to measures of illness severity and personality characteristics. Plasma cortisol was assessed to measure the influence of AVP release on the HPA axis, AVP being a secretagogue of adrenocorticotropic hormone (ACTH) that acts synergetically with CRH on ACTH release (Antoni 1986).

\section{METHODS}

Patients participating in this study fulfilled the DSMIII-R criteria for a major depressive episode. They were recruited from the routine clinical care group of the inpatient Depression Unit of the Psychiatric Hospital Endegeest, and from the Jelgersma out-patient clinic (Oegstgeest, The Netherlands). Patients with a history of medical illness (e.g., cardiovascular, neurological, endocrinological, oncological), hypertension or orthostatic hypotension, or medication that might affect the plasma levels of AVP, OT, or cortisol were excluded. Patients were required to be completely medication-free for at least 2 weeks before entering the study. None of the patients had used fluoxetine, because of the long half-life in plasma and because fluoxetine reduces CSF concentrations of AVP (De Bellis et al. 1993). Norepinephrine affects AVP output (Bisset and Chowdrey 1988). A washout period of 2 weeks suffices for normalization of the norepinephrine metabolites MHPG and MHPG-sulfate in patients on amitriptyline for 5 weeks (Van Kempen et al. 1992). Nine patients with severe anxiety or insomnia were allowed a maximum of $10 \mathrm{mg} / \mathrm{d}$ clorazepate, oxazepam or temazepam (five men and four women). All patients and normal controls underwent routine blood analysis, including renal and liver function tests and hematological measures. The study was approved by the Medical Ethical Committee of the Leiden University Hospital. Written informed consent was obtained after complete description of the study to both patients and controls.

Fifty-six depressed patients entered the study. Of these, two were excluded: one having developed multiple sclerosis the year after the index episode of major depression, and the other subsequently appearing to use large amounts of alcohol in spite of statements in the interviews. A further two had missing neuropeptide values and thus were excluded. A total of 52 patients ( 22 men, 30 women; mean age 44.8 years, SD 13.9, range 22-77) remained in the study. Eighteen were inpatients of the Depression Unit, and 34 were out-patients. Eleven men and 13 women were smokers. All patients refrained from the use of alcohol and from abnormal motor activity (sports) during the 12-h period preceding the study and during the day of blood sampling. All subjects were seated $15 \mathrm{~min}$ before venipuncture. Smoking was prohibited during the 30 min preceding venipuncture, but eating and drinking were ad libitum.

Forty-eight healthy controls were recruited via an advertisement in the local newspapers. Exclusion criteria for controls were: a life-time or present history of mental illness, screened with the semistructured interview of the CPRS (Åsberg et al. 1978), a present medical illness or use of medication, current stressful events or recent circadian shifts (working in day- and nightshifts, working until late in a bar, etc.). Accordingly, 37 subjects were selected (17 men, 20 women; mean age 41.2 years, SD 15.5, range 19-73). Five were smokers (two men and three women). Controls received the same instructions as did patients.

\section{Psychiatric Assessment}

The diagnosis was made according to the DSM-III-R criteria (American Psychiatric Association 1987) for a major depressive episode by a research psychiatrist (LvL). The sample consisted of six bipolar depressed, two psychotic depressed, and 44 non-psychotic depressed patients. For 30 of the 52 patients, the index episode was characterized as melancholic subtype (DSM-III-R criteria). Psychopathological symptoms and intensity ratings were assessed with the semistandardized interview of the Comprehensive Psychopathological Rating Scale (CPRS, Asberg et al. 1978) and two subscales, the Montgomery and Åsberg Depression Rating Scale (MADRS, Montgomery and Åsberg 1979), and the Brief 
Anxiety Scale (BAS, Tyrer et al. 1985), each item rated from $0-6$. Scores of at least 20 on the MADRS were required before entry. Psychomotor retardation was rated with the Salpêtrière Retardation Rating Scale (SRRS, Widlöcher 1983). Neuroticism, extraversion, psychoticism, and lie-scale, as personality dimensions, were evaluated using the Eysenck Personality Questionnaire (Eysenck and Eysenck 1975).

\section{Biochemical Assay Procedures}

Blood samples, $50 \mathrm{ml}$, were drawn by venipuncture consecutively at three different time points $(08.00,16.00$, and 23.00 hours) in one day. Blood for AVP and OT analysis was sampled in 10-ml chilled plastic tubes containing $1.6 \mathrm{mg} \mathrm{K-EDTA} / \mathrm{ml}$ blood. The plasma was immediately separated off at $4^{\circ} \mathrm{C}$, and was stored at $-80^{\circ} \mathrm{C}$ to await AVP and OT analysis. Plasma AVP and OT samples were radioimmunoassayed (RIA) in duplicate after extraction of peptides from plasma (efficiency $\sim 100 \%$ ) using C-8 Bond Elut ${ }^{\circledR}$ cartridges (Analytichem International, Harbour City, California USA), essentially as described previously (Van de Heijning et al. 1991). A rabbit antiserum (coded W1E) with the following crossreactivities: vasotocin $100 \%$; [Cyt $\left.{ }^{6}\right] \mathrm{AVP}-(3-9)$ 50\%; [pGlu, $\left.\mathrm{Cyt}^{6}\right]$ AVP-(4-9) 25\%; [Cyt $\left.{ }^{6}\right]$ AVP-(5-9) 13\%; AVP-(1-8), AVP-(1-7) and OT undetectable, was used for RIA of AVP. The detection limit was $0.5 \mathrm{pg} /$ tube, yielding a sensitivity of $0.5 \mathrm{pg} / \mathrm{ml}$ for plasma (extracted assay). The intraand interassay coefficients of variation were 9.9 and $15.9 \%$, respectively. OT was determined using the highly specific antiserum THF-3 donated by Dr. Higuchi (Matsuoka, Japan). For details on cross-reactivity, see Higuchi et al. (1985). The sensitivity of the assay was $0.5 \mathrm{pg} /$ tube $(0.5 \mathrm{pg} / \mathrm{ml}$ plasma $)$. Intra- and interassay coefficients of variation were $7 \%$ and $10 \%$, respectively.

Blood samples for cortisol determination were drawn into $\mathrm{NH} 4$-heparin-containing tubes and stored at $-20^{\circ} \mathrm{C}$ prior to assay by high performance liquid chromotography (HPLC) with UV detection. After thawing and before assay, prednisolone was added as internal standard. The plasma was alkalinized and cortisol was extracted into dichloromethane; after evaporation of the organic solvent, the sample was dissolved in the eluent then injected on an HPLC cartridge $\mathrm{CP}_{\mathrm{tm}}$ SPHER Si. The eluent consisted of a mixture of $335 \mathrm{ml}$ dichloromethane, 150 $\mathrm{ml}$ dichloromethane saturated with water, $6 \mathrm{ml}$ tetrahydrofuran, $12 \mathrm{ml}$ methanol, and $0.25 \mathrm{ml}$ acetic acid. The lower limit of detection at the wavelength used (254 $\mathrm{nm}$ ) was $10 \mathrm{nmol} / 1$ plasma; within-day and day-to-day variation were $4.6 \%$ and $8.7 \%$, respectively. Clinical and laboratory results were obtained independently. AVP and OT were measured in the Rudolf Magnus Institute for Neurosciences (Utrecht, The Netherlands); cortisol, osmolality and sodium were determined in the laboratory of the Endegeest Psychiatric Hospital (Oegstgeest,
The Netherlands). Samples from in- and out-patients and controls were run together in each assay.

\section{Organization of Results and Statistical Analysis}

The SPSS/PC + V5.02 (SPSS INC, Chicago, IL) was used for analysis. Patients and controls were compared with respect to sex, smoking, menopausal status, and use of oral contraceptives using the $\chi^{2}$ test. The significance of differences between patients and controls with regard to age was assessed with the two-tailed Student's $t$-test. Differences in hormone assay results between diagnostic groups were evaluated by repeated measures analysis of variance (RM-ANOVA). In cases where RMANOVA showed significance, we tested for pairwise significance with sex as a second factor and age as covariate (ANCOVA). Levene's test was used to compare equality of variances. Multiple regression analysis was applied to relate hormone data with sex, age, reproductive status, use of benzodiazepines or smoking in patients and controls. Correlations between hormone data and psychopathology and personality dimensions were tested by calculation of the Spearman rank correlation coefficient (rho). Two-tailed probabilities were applied throughout, unless otherwise stated. Significance was set at $p<.05$. Type I errors were avoided as the Bonferroni equation was used for multiple comparisons.

\section{RESULTS}

\section{Possible Confounding Factors}

Patients' levels of plasma AVP and OT were not related to sex, age, smoking, menopausal status, use of oral contraceptives or benzodiazepines $(n=9)$, or any mutual interaction of these parameters (multiple regression analysis). In controls, the men had higher mean plasma AVP than did the women $(F=6.20, d f=1,35, p=.018)$, but there was no time effect or group by time effect $(F=$ $0.61, d f=2,70, p=.54)$. Similarly, male controls had a higher mean plasma OT than did female controls $(F=$ $4.46, d f=1,35, p=.042$ ), with no time effect or group by time effect $(F=1.06, d f=2,70, p=.35)$. Although in the patients group plasma AVP and OT did not show a relationship with sex or age, we did adjust the following comparisons for sex and age (Os et al. 1985). Patients and controls were not significantly different regarding sex, age, menopausal status, and use of oral contraceptives (Table 1). As expected, the group of patients included more smokers $\left(\chi^{2}=8.46, d f=1, p=.004\right)$.

\section{Plasma AVP, OT, Cortisol}

Table 2 shows that the patients had a significantly higher mean plasma AVP and cortisol and lower mean 
Table 1. Characteristics of Subjects Enrolled in the Study

\begin{tabular}{lccc}
\hline & $\begin{array}{c}\text { Melancholic } \\
\text { Patients } \\
(\boldsymbol{n}=\mathbf{3 0 )}\end{array}$ & $\begin{array}{c}\text { Nonmelancholic } \\
\text { Patients } \\
(\boldsymbol{n}=\mathbf{2 2})\end{array}$ & $\begin{array}{c}\text { Controls } \\
(\boldsymbol{n}=\mathbf{3 7})\end{array}$ \\
\hline Sex M : F & $15: 15$ & $7: 15$ & $17: 20$ \\
In-patient : out-patient & $15: 15$ & $3: 19$ & - \\
Benzodiazepine yes : no & $7: 23$ & $2: 20$ & $12: 10$ \\
Smokers : nonsmokers & $12: 18$ & $10: 5$ & $5: 32$ \\
Premenopausal : postmenopausal & $9: 6$ & 3 & $14: 6$ \\
Oral contraceptives & 4 & $41.6 \pm 12.3($ SE 2.6) & 2 \\
Age & $47.1 \pm \mathbf{1 4 . 8 ( S E ~ 2 . 7 )}$ & $41.2 \pm 15.5($ SE 2.6) \\
\hline
\end{tabular}

plasma osmolality and sodium than did the controls. No significant differences were found between mean plasma levels of OT in patients and controls. There was a significant time effect only for cortisol. The course of osmolality throughout the day was significantly different between patients and controls (group by time effect).

\section{Plasma AVP}

Figure 1 shows individual plasma AVP values for each patient and control subject. Sixteen of the 52 patients had values clearly above the cut-off level of $14 \mathrm{pg} / \mathrm{ml}$ plasma defined as the mean plus twice the standard deviation of the controls. Levene's test for equality of variances showed significant differences in the distribution of AVP concentrations between patients and controls (Figure 1). The AVP plasma values did not vary widely in the same individual (in either patients or controls), when the values from the three daily determinations were compared. When adjusted for sex and age, the dif- ferences between plasma AVP of patients and controls were significant at 8.00, 16.00, and 23.00 hours (Table 2).

Table 3 shows that the in-patients had higher mean levels of plasma AVP than did the out-patients. The inpatients had higher plasma AVP than the controls at all three time-points (respectively, $p<.001$ at 8.00 hours; $p=.001$ at 16.00 hours; $p=.002$ at 23.00 hours adjusted for sex and age). The out-patients had significantly higher plasma AVP levels than the controls at 16.00 hours $(t=2.0, d f=55.9, p=.05)$. The patients with melancholic subtype of depression had higher levels of plasma AVP at 23.00 hours than did patients with the nonmelancholic subtype $(t=2.04, d f=50, p=.05)$.

\section{Subgroup of Patients with Vasopressin Levels > $14 \mathrm{pg} / \mathrm{ml}$ Plasma}

The 16 patients who had AVP levels above the cut-off level of $14 \mathrm{pg} / \mathrm{ml}$ plasma, included seven males and nine females (five premenopausal of whom one used an oral contraceptive), eight out-patients and eight in-patients,

Table 2. Mean (SD) of Plasma Vasopressin, Oxytocin, Osmolality, and Sodium Concentrations in Patients $(n=52)$ and Controls $(n=37)$

\begin{tabular}{|c|c|c|c|c|c|c|c|c|c|c|c|c|c|}
\hline & & \multirow[b]{2}{*}{08.00 hours } & \multirow[b]{2}{*}{$p^{*}$} & \multirow[b]{2}{*}{16.00 hours } & \multirow[b]{2}{*}{$p^{*}$} & \multirow[b]{2}{*}{23.00 hours } & \multirow[b]{2}{*}{$p^{*}$} & \multicolumn{2}{|c|}{$\begin{array}{c}\text { Time Effect } \\
d f=2,174\end{array}$} & \multicolumn{2}{|c|}{$\begin{array}{c}\text { Group } \times \\
\text { Time } \\
\text { Effect } \\
d f=2,174 \\
\end{array}$} & \multicolumn{2}{|c|}{$\begin{array}{c}\text { Group } \\
\text { Differences } \\
d f=1,87\end{array}$} \\
\hline & & & & & & & & $F$ & $p$ & $F$ & $p$ & $F$ & $p$ \\
\hline Vasopressin & $\mathrm{P}$ & $8.94(7.25)$ & 0.007 & $9.16(7.43)$ & 0.007 & $8.07(5.94)$ & 0.014 & 1.58 & 0.21 & 1.11 & 0.33 & 7.98 & 0.006 \\
\hline & C & $1.28(0.57)$ & & $1.28(0.53)$ & & $1.44(0.72)$ & & & & & & & \\
\hline \multirow[t]{2}{*}{ Cortisol } & $\mathrm{P}$ & $0.59(0.19)$ & 0.011 & $0.34(0.15)$ & 0.005 & $0.22(0.14)$ & 0.007 & 223.07 & $<0.001$ & 0.23 & 0.80 & 12.12 & 0.001 \\
\hline & $\mathrm{C}$ & $0.49(0.17)$ & & $0.25(0.13)$ & & $0.14(0.08)$ & & & & & & & \\
\hline \multirow[t]{2}{*}{ Osmolality } & $\mathrm{P}$ & $291.27(5.30)$ & 0.117 & $290.02(6.05)$ & $<0.001$ & $290.35(5.86)$ & $<0.001$ & 0.94 & 0.39 & 5.02 & 0.008 & 14.73 & $<0.001$ \\
\hline & $\mathrm{C}$ & $293.00(7.59)$ & & $294.84(5.15)$ & & $296.27(7.60)$ & & & & & & & \\
\hline Sodium & $\mathbf{P}$ & $140.46(2.36)$ & 0.199 & $140.42(2.24)$ & 0.085 & $140.19(2.44)$ & 0.017 & 0.09 & 0.92 & 0.88 & 0.42 & 4.60 & 0.035 \\
\hline
\end{tabular}

Vasopressin and oxytocin in $\mathrm{pg} / \mathrm{ml}$, cortisol in $\mu \mathrm{mol} / \mathrm{l}$, osmolality in mosm $/ \mathrm{l}$, sodium in $\mathrm{mmol} / \mathrm{l} ; \mathrm{P}=$ patients; C $=$ controls.

$p^{*}$ differences between patients and controls with sex as a second factor adjusted for age (ANCOVA). 


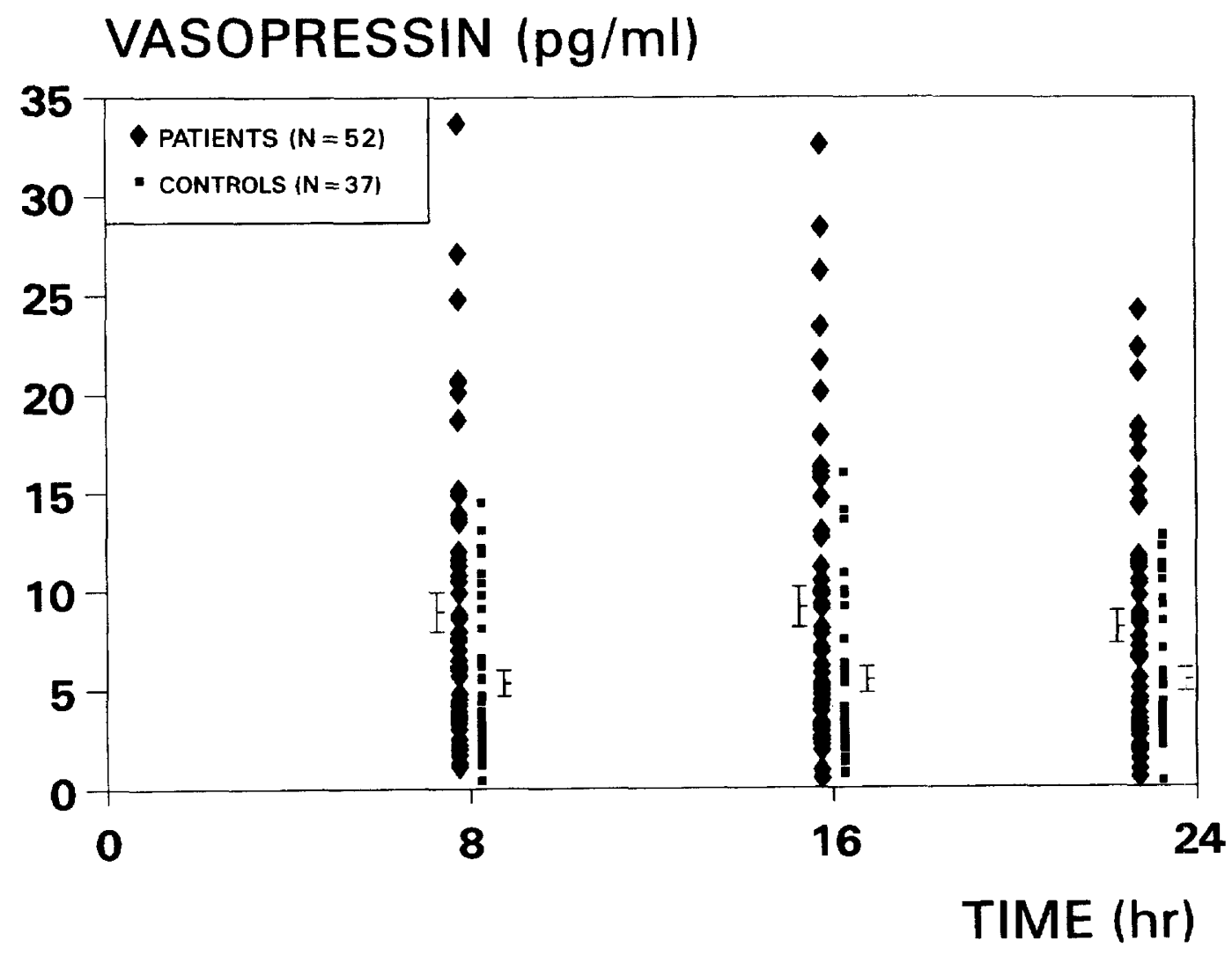

Figure 1. Plasma arginine vasopressin (AVP) levels in patients with major depression and controls. Mean plasma levels of AVP of patients were significantly increased at all three time-points compared to controls (respectively, $p=.007, p=.007$, $p=.014$, ANCOVA with sex as second factor and age as covariate). The distribution of AVP values showed significant differences between patients and controls $(8.00$ hours $p=.007 ; 16.00$ hours $p=.006 ; 23.00$ hours $p=.005$ Levene's test for equality of variances). Error bars indicate mean \pm SEM.

nine first episodes and seven recurrent depressions, six smokers and 10 nonsmokers. The patients with high AVP levels were not significantly different from the other patients in age $(p=.87)$ and use of a benzodiazepine (only one patient).

\section{Plasma Oxytocin}

In four of the 52 patients and three of the 37 controls, the plasma OT level was below our detection limit of $0.5 \mathrm{mg} / \mathrm{ml}$. The mean OT plasma concentrations were not significantly different between depressed patients

Table 3. Mean (SD) Vasopressin (AVP) and Oxytocin (OT) Concentrations (pg/ml) According to Patient Characteristics $(n=52)$

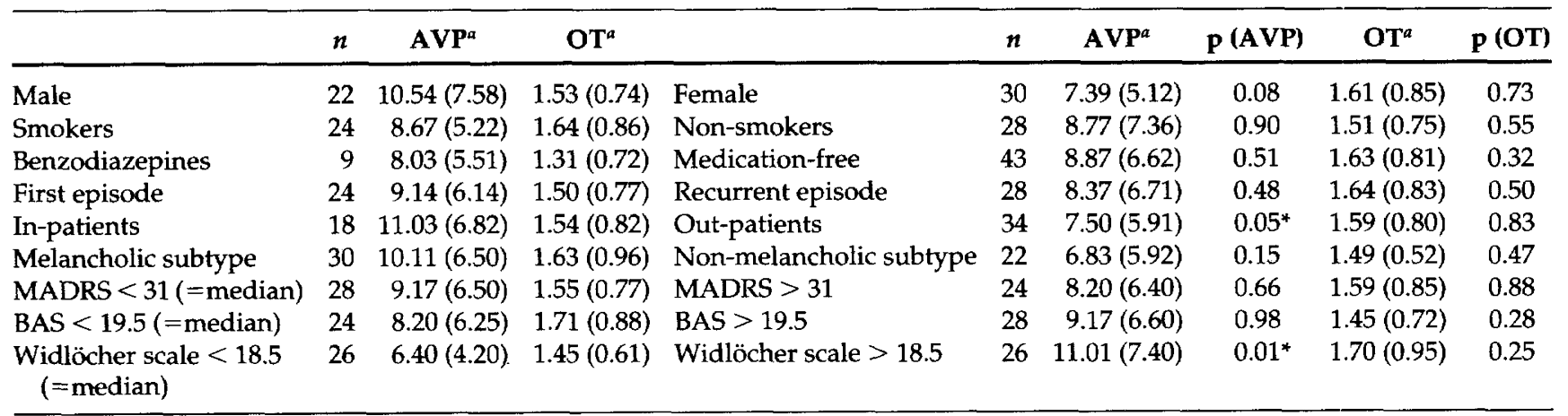

${ }^{\circ}$ The AVP and OT values represent an average of the three determinations for each timepoint $(8.00,16.00$, and 23.00 hours).

Statistics by ANCOVA with sex as a second factor (except in the first comparison) and age as covariate. 
and controls, although the patients showed a trend towards higher levels (Table 2). The mean daily OT plasma concentrations were more widely distributed in patients than in controls (Levene's test for equality of variances, $p=.017)$.

\section{Plasma Cortisol}

The mean plasma cortisol levels were significantly higher in patients than in controls at all three samplings (Table 2). The in-patients did not have a higher mean level of plasma cortisol than did the out-patients $(t=$ $0.28, d f=49, p=.78$ ).

\section{Correlation between Plasma AVP, OT, and Cortisol}

There was no significant correlation between levels of AVP, OT, and cortisol in plasma of controls, patients, or the total sample at any of the sampling times after Bonferroni correction for multiple testing.

\section{Plasma Osmolality and Sodium}

Mean plasma osmolality was significantly lower in patients than in controls at 16.00 hours and 23.00 hours (Table 2). There was no significant difference between plasma osmolality of the subgroup of 16 patients with AVP levels $>14 \mathrm{pg} / \mathrm{ml}$ and that of the other patients. The mean plasma sodium levels were lower in patients than in controls at 23.00 hours (Table 2), but were not related to plasma levels of AVP. Patients with melancholic subtype had lower plasma sodium than did the controls at 16.00 hours and 23.00 hours $(t=2.53$, df $=$ $64, p=.014 ; t=2.09, d f=65, p=.041)$. Patients with the nonmelancholic subtype had a plasma sodium not significantly different from that of controls.

\section{Hormonal Data, Psychopathological Rating Scales, and Personality Dimensions}

The mean plasma AVP concentrations showed a correlation with the scores for psychomotor retardation on the Widlöcher scale ( $r h o=0.2982, p=.032$ ) for the entire patient sample. Mean plasma AVP concentrations and neuroticism were inversely correlated $(r h o=-0.5079$, $p=.001)$. Since 8 comparisons were made, the Bonferroni-corrected $p$ value would be $0.05 / 8=0.006$, which was met by the correlation between plasma AVP and neuroticism. The significance of this correlation was due to the input of patients with recurrent episodes (see below). No significant correlations were found between the mean plasma AVP level and scores on the other rating scales.

When the patient group was divided into those for whom the index episode was the first episode $(n=24)$, and those for whom it was a recurrent episode $(n=28)$, patients with first episodes had lower scores for neuroticism $(15.1 \pm 4.5)$ than did patients with recurrent episodes (17.3 $\pm 5.4, U=136.5, p=.035$, Mann-Whitney $U$-test). Patients with recurrent episodes had mean plasma AVP concentrations that correlated strongly with neuroticism (rho $=-0.6214, p=.002$, significant after Bonferroni correction), whereas plasma AVP levels did not correlate significantly with neuroticism in the first-episode group.

Mean plasma levels of OT and cortisol were not significantly correlated to any of the rating scales after correction for the number of comparisons $(p<.006)$.

\section{DISCUSSION}

This is the first report of elevated AVP concentrations in a sample of depressed patients (up to $33.7 \mathrm{pg} / \mathrm{ml}$ plasma), most of whom were completely drug free. None of them were on antidepressants or antipsychotic medication. The AVP values we measured in our assay were considerably high: $31 \%$ of the patients had AVP plasma concentrations higher than the mean plus 2 SDs of the normal controls. These high levels of plasma AVP were found in in-patients as well as in out-patients and not in any of the controls.

Significant differences in baseline plasma AVP between depressed patients and controls have not been found earlier (Raskind et al. 1979; Gjerris et al. 1985; Sörensen et al. 1985; Ritchie et al. 1991). In most, if not all of these studies, AVP concentrations were only assessed once daily, usually in the morning. Furthermore, in most of these studies the patient sample was small (Raskind et al. 1979). Data from the same patient population were used for two reports, and seriously neurologically ill patients were the controls (Gjerris et al. 1985; Sörensen et al. 1985). Finally, the results of the most recent study using a large number of patients have unfortunately only appeared in abstract form (Ritchie et al. 1991). With regard to the CSF concentrations of AVP, depressed patients showed significantly lower values than normal controls (Gold et al. 1984; Gjerris et al. 1985), but higher than normal values were found in patients with psychotic depression (De Bellis et al. 1993). No significant difference in CSF OT was found between depressed patients and controls (Demitrack and Gold 1988).

In considering our results, some inevitable limitations of the design should be kept in mind. The food and water intake of the subjects was ad libitum, inducing a methodological weakness. Strict control, however, would have excluded severely depressed subjects (for ethical reasons), and out-patients (for probable noncompliance). These exclusions would have yielded a small patient sample, made up of moderately depressed individuals. We did exclude major factors 
known to influence plasma AVP levels, e.g., alcohol, medication, blood pressure instability, hypovolemia, hyponatremia, hyperosmolality, and dehydration, and we controlled for sex and age. Cigarette smoking increases plasma AVP concentration (Waeber et al. 1984). We prohibited smoking during the 30 min preceding venipuncture. This was done to avoid acute nicotine withdrawal symptoms. We did include smokers in our sample, to eliminate bias from dropping out of severely depressed smokers and, in general, from noncompliance. Anyhow, the high levels of plasma AVP could not be accounted for by smoker status (Table 3).

Male controls had significantly higher plasma AVP levels than did the female controls. Similar results have been reported in an elderly population (Asplund and Aberg 1991). This observation and our results suggest that sex hormones and the secretion of AVP may be related. Plasma AVP is reported to be lower during menstruation than at ovulation (Forsling et al. 1981). Five of the eight women in the subgroup of 16 patients with high plasma AVP were premenstrual. The phase of the menstrual cycle of these five premenstrual women is unlikely to have influenced the results in an upward direction (mean AVP $12.01 \pm 3.51 \mathrm{pg} / \mathrm{ml}$ ), as the male patients had the highest values for plasma AVP (mean AVP $19.75 \pm 5.6 \mathrm{pg} / \mathrm{ml}$ ).

Chlordiazepoxide pretreatment decreases basal levels of plasma vasopressin in rats (Wible et al. 1985), but we found no significant difference between the plasma AVP of the nine patients who were using a benzodiazepine (mainly clorazepate) and the plasma AVP of medication-free patients (Table 3 ).

We found higher mean levels of plasma AVP in patients with DSM-III-R melancholic subtype than in patients with nonmelancholic subtype depression, suggesting that the two subtypes of mood disorder-the melancholic and the neurotic or dysthymic subtypecould be differently related to AVP secretion. Syvaelahti (1985) did not find a difference in plasma AVP levels between endogenous and nonendogenous depressed patients, when using the Newcastle scale. Our groups were defined according to DSM-III-R criteria.

The in-patients showed significantly higher mean plasma AVP levels than did the out-patients. However, the major finding of this study that the depressed patients had significantly higher plasma levels of AVP than the controls is not attributable only to the high levels of plasma AVP of the in-patients. Factors that might contribute to the higher basal plasma AVP levels of the in-patients were that the in-patients were more severely depressed than the out-patients, that there were more patients with melancholic subtype among the in-patients, and that hospitalization in itself is a major stress factor (Maes et al. 1994). Both in- and out-patients had a mean plasma cortisol higher than controls, which is not in agreement with the findings of Maes et al.
(1994), where hypercortisolism was a feature only of the in-patients.

The mechanisms of increased AVP plasma concentrations in major depression remain to be explored. It is unlikely that higher levels of plasma AVP in our patients were caused by increased plasma osmolality. Patients showed lower blood osmolality and sodium levels than controls later in the day, and this may have been the result of the increased plasma AVP levels that were present in the morning. It is known that plasma AVP and OT are synthesized in the magnocellular neurons of the hypothalamic paraventricular (PVN), supraoptic (SON), and accessory nuclei (De Wied et al. 1993). These neurons project to the posterior pituitary, and it is from here that AVP and OT are released into the general circulation. Parvocellular AVP- and OTcontaining neurons of the PVN project to the external lamina of the median eminence, where the hormones are released into the portal vessel system to regulate anterior pituitary function. Magno- and parvocellular AVP- and OT-containing neurons also project to other areas inside the CNS (Landgraf 1992; Morris and Pow 1993). The release of AVP and OT in the general circulation could be paralleled by peptide release in certain target sites in the brain. Plasma AVP and OT concentrations may thus reflect the activity of a subgroup of AVP-synthesizing cells in the CNS. One can argue that although central and peripheral AVP and OT are regulated differently under normal physiological conditions, peptide release in certain target sites in the CNS under conditions of stress may be paralleled by release in plasma under the influence of a shared central mechanism. In other words, it could be possible that under the influence of (repeated) stress, increased synthesis of AVP and CRH is evoked (Holsboer 1995), and that this production of central AVP is paralleled by a release of AVP in the general circulation. Another possibility that may play a role in the mechanism of increased plasma AVP levels in major depression is suggested by Maes et al. (1993), when they found a lower serum prolyl endopeptidase (PEP) in patients with major depression. PEP is a serine proteinase that degrades substrates such as AVP. Thus, lower PEP activity may lead to increased concentrations of AVP (Maes et al. 1993).

\section{Plasma AVP and Psychomotor Retardation}

Plasma AVP concentrations were higher in patients with severe psychomotor retardation than in patients with mild or no symptoms of psychomotor retardation. The correlation between mean levels of plasma AVP and scores on the Widlöcher scale was found not to be significant after Bonferroni correction. Since this was an exploratory study, we do consider that this possible relationship may be indicative of a trend. Although immobilization in rats is very different from psychomotor 
retardation in humans, it is interesting to note that repeated immobilization stress (De Goeij et al. 1992a) and chronic psychosocial stress (De Goeij et al. 1992b) enhanced vasopressin synthesis in CRF neurons of the paraventricular nucleus in rats.

\section{Plasma AVP and Neuroticism}

Plasma AVP was inversely associated with neuroticism. The significance of this correlation was due to the input of patients with a recurrent depressive episode who had high levels of neuroticism. Neuroticism is strongly related to both lifetime and 1-year prevalence of major depression (Kendler et al. 1993). In that respect, it might be interesting to look for the predictive value of high or low plasma AVP concentrations and bad outcome.

The plasma OT concentrations of patients varied over a wide range, so that no changes were significant. There was, though, a trend to elevated levels. The increased levels of basal plasma cortisol in the depressed patients were consistent with the hyperactivity of the HPA axis in patients with major depression (Carroll 1972). A correlation between plasma AVP and cortisol levels could have been expected because of the involvement of AVP in the ACTH response to stress (Bisset and Chowdrey 1988), but was not found.

To summarize in brief, we found elevated plasma concentrations of AVP in our sample of depressed patients. These results suggest that AVP could play a role in the clinical picture of major depression, either directly, or indirectly as a mediator of the HPA axis.

\section{ACKNOWLEDGMENTS}

This study was supported by the Netherlands Organization for Scientific Research (Grant KWO 900-548-117). The authors thank the Endegeest Psychiatric Hospital for laboratory assistance.

\section{REFERENCES}

American Psychiatric Association (1987): Diagnostic and Statistical Manual of Mental Disorders, 3rd ed rev. Washington, DC, APA Press

Antoni FA (1986): Hypothalamic control of adrenocorticotropin secretion: Advances since the discovery of 41-residue corticotropin-releasing factor. Endocr Rev 7:351-381

Åsberg M, Montgomery S, Perris C, Schalling D, Sedvall G (1978): A comprehensive psychopathological rating scale. Acta Psychiatr Scand 271(suppl):5-27

Asplund R, Aberg H (1991): Diurnal variation in the levels of antidiuretic hormone in the elderly. J Intern Med 229: 131-134

Auböck J, Konzett H (1983): Ischaemic pain versus mental task: Effect on plasma vasopressin in man. Pain 15:93-99
Bartanuzs V, Jezova D, Bertini LT, Tilders FJH, Aubry IM, Kiss JZ (1993): Stress-induced increase in vasopressin and corticotropin-releasing factor expression in hypophysiotrophic paraventricular neurons. Endocrinology 132:895-902

Bisset GW, Chowdrey HS (1988): Control of release of vasopressin by neuroendocrine reflexes. Quart J Exp Physiol 73:811-872

Carroll BJ (1972): The hypothalamic pituitary adrenal axis in depression. In Davies B, Carroll B, Mowbray R (eds), Depressive Illness: Some Research Studies. Springfield, IL, C.C. Thomas, pp 23-201

De Bellis MD, Gold PW, Geracioti TD, Listwak SJ, Kling MA (1993): Association of fluoxetine treatment with reductions in CSF concentrations of corticotropin-releasing hormone and arginine vasopressin in patients with major depression. Am J Psychiatry 150:656-657

De Goeij DCE, Jezova D, Tilders FJH (1992a): Repeated stress enhances vasopressin synthesis in corticotropin releasing factor neurons in the paraventricular nucleus. Brain Res 577:165-168

De Goeij DCE, Dijkstra H, Tilders FIH (1992b): Chronic psychosocial stress enhances vasopressin, but not corticotropin-releasing factor, in the external zone of the median eminence of male rats: Relationship to subordinate status. Endocrinology 131:847-853

Demitrack M, Gold PW (1988): Oxytocin: Neurobiologic considerations and their implications for affective illness. Prog Neuro-Psychopharmacol \& Biol Psychiatry 12: S23-S51

De Wied D, Diamant M, Fodor M (1993): Central nervous system effects of the neurohypophyseal hormones and related peptides. Front Neuroendocrinol 14:251-302

Edelson JT, Robertson GL (1986): The effect of the cold pressor test on vasopressin secretion in man. Psychoneuroendocrinology 3:307-316

Eysenck HJ, Eysenck SBG (1975): Manual of the Eysenck Personality Questionnaire. London, Hodder \&: Stoughton Educational

Forsling ML, Åkerlund M, Strömberg P (1981): Variations in plasma concentrations of vasopressin during the menstrual cycle. I Endocrinol 89:263-266

Fruhstorfer B, Pritsch MG, Ott P (1986): Effects of daytime noise load on the sleep-wake cycle and endocrine patterns in man. II. 24 hours secretion of anterior and posterior pituitary hormones and of cortisol. Int J Neurosci 39:211-221

Gibbs DM (1986): Vasopressin and oxytocin: Hypothalamic modulators of the stress response. A review. Psychoneuroendocrinology 11:131-140

Gjerris A, Hammer M, Vendsborg P, Christensen NJ, Rafaelsen OJ (1985): Cerebrospinal fluid vasopressinchanges in depression. Br J Psychiatry 147:696-701

Gold PW, Goodwin FK, Reus VI (1978): Vasopressin in affective illness. Lancet i:1233-1235

Gold PW, Ballenger JC, Robertson GL, Weingartner H, Rubinow DR, Hoban MC, Goodwin FK, Post RM (1984): Vasopressin in affective illness: Direct measurement, clinical trials, and response to hypertonic saline. In Post RM, Ballenger JC (eds), Neurobiology of Mood Disor- 
ders, vol 1. Baltimore/London, Williams \& Wilkins, pp 323-339

Higuchi T, Honda K, Fukuoka T, Negoro H, Wakabayashi K (1985): Release of oxytocin during suckling and parturition in the rat. J Endocrinol 105:339-346

Holsboer F (1996): Neuroendocrine studies in depression. Eur Neuropsychopharmacol 6(suppl 4):S4-1

Holsboer F (1995): Neuroendocrinology of mood disorders. In Bloom FE, Kupfer DJ (eds), Psychopharmacology: The Fourth Generation of Progress. New York, Raven Press, Ltd, pp 957-969

Ivanyi T, Wiegant VM, De Wied D (1991): Differential effects of emotional and physical stress on the central and peripheral secretion of neurohypophysial hormones in male rats. Life Sci 48:1309-1316

Kendler KS, Weitzman RE, Fisher DA (1978): The effect of pain on plasma arginine vasopressin concentrations in man. Clin Endocrinol 8:89-94

Kendler KS, Neale MC, Kessler RC, Heath AC, Eaves LJ (1993): A longitudinal twin study of personality and major depression in women. Arch Gen Psychiatry 50: 853-862

Landgraf $R$ (1992): Central release of vasopressin: Stimuli, dynamics, consequences. In Ermisch A, Landgraf $R$, Rühle $\mathrm{H}-\mathrm{J}$ (eds), Circumventricular Organs and Brain Fluid Environment: Molecular and Functional Aspects. Prog Brain Res. Amsterdam, Elsevier, 91, pp 29-39

Maes M, Calabrese J, Meltzer HY (1993): The relevance of the in- versus outpatients status for studies on HPA-axis in depression: Spontaneous hypercortisolism is a feature of major depressed inpatients and not of major depression per se. Prog Neuro-Psychopharmacol \& Biol Psychiatry 19:503-517

Maes M, Goossens F, Scharpé S, Meltzer HY, D'Hondt P, Cosyns P (1994): Lower serum prolyl endopeptidase enzyme activity in major depression: Further evidence that peptidases play a role in the pathophysiology of depression. Biol Psychiatry 35:545-552

Maillet A, Gunga HC, Gauquelin G, Fortrat JO, Hope A, Rocker L, Kirsch K, Gharib C (1993): Effects of 28-day isolation (ESA-ISEMSI'90) on blood pressure and blood volume regulating hormones. Aviat Space Environ Med 64:287-294

Meyerhoff JL, Oleshansky MA, Kalogeras KT, Mougey EH, Chrousos GP, Granger LG (1990): Neuroendocrine responses to emotional stress: Possible interactions between circulating factors and anterior pituitary hormone release. Advances in Experimental Medicine and Biology. In Porter JC, Jezova D (eds), Circulating Regulatory Factors and Neuroendocrine Function, vol 274. New York, Plenum Press, pp 91-111

Montgomery SA, Åsberg M (1979): A new depression scale designed to be sensitive to change. $\mathrm{Br} \mathrm{J}$ Psychiatry 134:382-389

Morris JF, Pow DV (1993): New anatomical insights into the inputs and outputs from hypothalamic magnocellular neurons. Ann NY Acad Sci 689:16-33
Os I, Kjeldsen SE, Aakesson I, Skjoto J, Eide I, Hjermann I, Leren P (1985): Evidence of age-related variation in plasma vasopressin of normotensive men. Scand J Clin Lab Invest 45:263-268

Purba JS, Hoogendijk WJG, Hofman MA, Swaab DF (1996): Increased numbers of vasopressin and oxytocin expressing neurons in the paraventricular nucleus of the human hypothalamus in depression. Arch Gen Psychiatry 53: 137-143

Raskind MA, Orenstein H, Weitzman RE (1979): Vasopressin in depression. Lancet i:164

Ritchie JC, Bragg DC, White N, Krishnan KRR, Caroll BJ (1991): Plasma vasopressin and ACTH baseline levels in depression. Neuroendocrinol Lett 13:208 (abstract)

Sanders G, Freilicher J, Lightman SL (1990): Psychological stress of exposure to uncontrollable noise increases plasma oxytocin in high emotionality women. Psychoneuroendocrinology 15:47-58

Sörensen PS, Gjerris A, Hammer M (1985): Cerebrospinal fluid vasopressin in neurological and psychiatric disorders. J Neurol Neurosurg Psychiatry 48:50-57

Stopa EG, King JC, Lydic R, Schoene WC (1984): Human brain contains vasopressin and vasoactive polypeptide neuronal subpopulations in the suprachiasmatic region. Brain Res 297:159-163

Syvaelahti E (1985): Dexamethasone suppression test and the levels of serum growth hormone, plasma vasopressin and plasma homovanillic acid in depressed inand outpatients. Acta Psychaitr Scand 71:105-110

Tyrer P, Owen RT, Cichetti DV (1984): The brief scale for anxiety: A subdivision of the Comprehensive Psychopathological Rating Scale. J Neurol Neurosurg Psychiatry 47:970-975

Van de Heijning BJM, Koekoek-Van den Herik I, Ivanyi T, Van Wimersma Greidanus TjB (1991): Solid-phase extraction of plasma vasopressin: Evaluation, validation and application. J Chromatography 565:159-171

Van Kempen GMJ, Zitman FG, Linssen ACG, Edelbroek PM (1992): Biochemical measures in patients with a somatoform pain disorder, before, during, and after treatment with amitriptyline with or without flupentixol. Biol Psychiatry 31:670-680

Waeber B, Schaller MD, Nussberger J, Bussien JP, Hofbauer KG, Brunner HR (1984): Skin blood flow reduction induced by cigarette smoking: Role of vasopressin. Am J Physiol 247:H895-H901

Watts AG, Swanson LW (1987): Efferent projections of the suprachiasmatic nucleus. II. Studies using retrograde transport of fluorescent dyes and simultaneous peptide immunohistochemistry in the rat. J Comp Neurol 258:230252

Wible JH, Zerbe RL, Dimicco JA (1985): Benzodiazepine receptors modulate circulating plasma arginine vasopressin concentration. Brain Res 359:368-370

Widlöcher DJ (1983): Psychomotor retardation: Clinical, theoretical and psychometric aspects. Psychiatr Clin North Am 6:27-40 